\title{
FROM MICROSCOPIC TO MACROSCOPIC PERSPECTIVES AND BACK: THE STUDY OF LEADERSHIP AND HEALTH/WELL-BEING
}

\author{
Editorial for the \\ Journal of Occupational Health Psychology Special Issue on Leadership and Health/Well- \\ being
}

\section{Guest Editors:}

Ilke Inceoglu, PhD, University of Exeter Business School

Kara A. Arnold, PhD, Memorial University, Faculty of Business Administration

Hannes Leroy, PhD, Rotterdam School of Management, University of Exeter Business School

Jonas W. B. Lang, PhD, Ghent University, University of Exeter Business School

Ute Stephan, PhD, King's College London, Technische Universität Dresden

Author note: The idea for a special issue on Leadership and Health/Well-being was an outcome of the discussions at the EAWOP Small Group on Leadership and Health/Well-being which took place at the University of Exeter in 2019.

Corresponding author: Ilke Inceoglu, University of Exeter Business School, University of Exeter, Streatham Court, Rennes Drive, Exeter EX4 4PU, UK. Email: i.inceoglu@exeter.ac.uk 


\begin{abstract}
This special issue introduces a set of papers that contribute to research on leadership and health/well-being from multiple perspectives. To situate these papers in current research debates, this introduction to the special issue provides an overview of research on leadership and health/well-being by using a microscope-macroscope perspective as an organizing framework. The microscope-macroscope organizing framework highlights that a comprehensive understanding of leadership and well-being requires researchers to include multiple perspectives, including those of leaders and followers, embedded in their context and time. It encourages researchers to transcend more narrow input-process-output perspectives that are typically adopted when studying leadership, health and well-being.
\end{abstract}

Keywords: Health; Well-being; Leadership; Interventions; Context 


\section{FROM MICROSCOPIC TO MACROSCOPIC PERSPECTIVES AND BACK: THE STUDY OF LEADERSHIP AND HEALTH/WELL-BEING}

Researchers, practitioners, and organizations have long sought to better understand many different aspects of leadership and health/well-being in research and practice. Given this interest, we were nevertheless impressed with the large number of proposals for this special issue. The relevance of this area of research has been underscored even more during the COVID-19 pandemic. That many leaders and employees manifestly experienced heightened levels of work demands and rapid changes, reminded organizations and employees how important leadership behavior and decisions can be in relation to leaders' own health/well-being and that of their employees.

Current research suggests that leaders' behavior can protect and support employees' wellbeing. For example, the extant literature provides evidence that constructive/destructive leadership styles in supervisors are associated with positive/negative well-being outcomes for employees (e.g., Harms et al., 2017; Inceoglu et al., 2018; Montano et al., 2017; Skakon et al., 2010). These relationships have been found to be explained by a multitude of variables, with some important work attempting to provide theoretical clarity to these mediators (e.g., Inceoglu et al., 2018) and with fewer studies examining moderators of these relationships (Arnold, 2017). Meta-analytic evidence demonstrates that it is important to also take into account the health/wellbeing of the leaders which is relevant to their own decision making and behavior (Kaluza et al., 2019) and to consider entrepreneurs as leaders who face unique challenges that impact wellbeing (Stephan, 2018).

In this introduction to the special issue, we provide an overview of research on leadership and health/well-being, using a microscope-macroscope perspective (e.g. Bamberger, 2008) as an 
organizing framework. This perspective transcends more narrow input-process-output perspectives that researchers typically adopt when studying leadership, health and well-being. The microscope/-macroscope organizing framework highlights that a comprehensive understanding of leadership and well-being requires researchers to include multiple perspectives, including those of leaders and followers, embedded in their context and time. Using this microscope-macroscope framework, we outline how each of the papers in the special issue fits into the broader landscape of this research area.

\section{THE MICROMACROSCOPE: A MODEL OF LEADERSHIP AND HEALTH/WELL- BEING}

Behaviors and health/well-being of leaders and followers are dynamic (e.g. Sonnentag, 2015) and do not take place in isolation - time and context matter. Research emphasizing the role of context has a long tradition in the organizational sciences. In developing a microscopemacroscope framework we build on Kurt Lewin's force-field theory $(1939,1942)$, John's (2006) model of context, and Oc's (2018) application of John's model to leadership theory, to view issues in leadership and health/well-being with a "microscope" and a "macroscope" - zooming in on health/well-being at the granular 'microscope' level and zooming out again to take into account the multi-layered context in which leaders and followers' work in and interact, in the 'macroscope'. As shown in Figure 1, such a micromacroscope perspective identifies several novel avenues for research on leadership and health/well-being. 
Figure 1: A microscopic and macroscopic framework of leadership and health/well-being

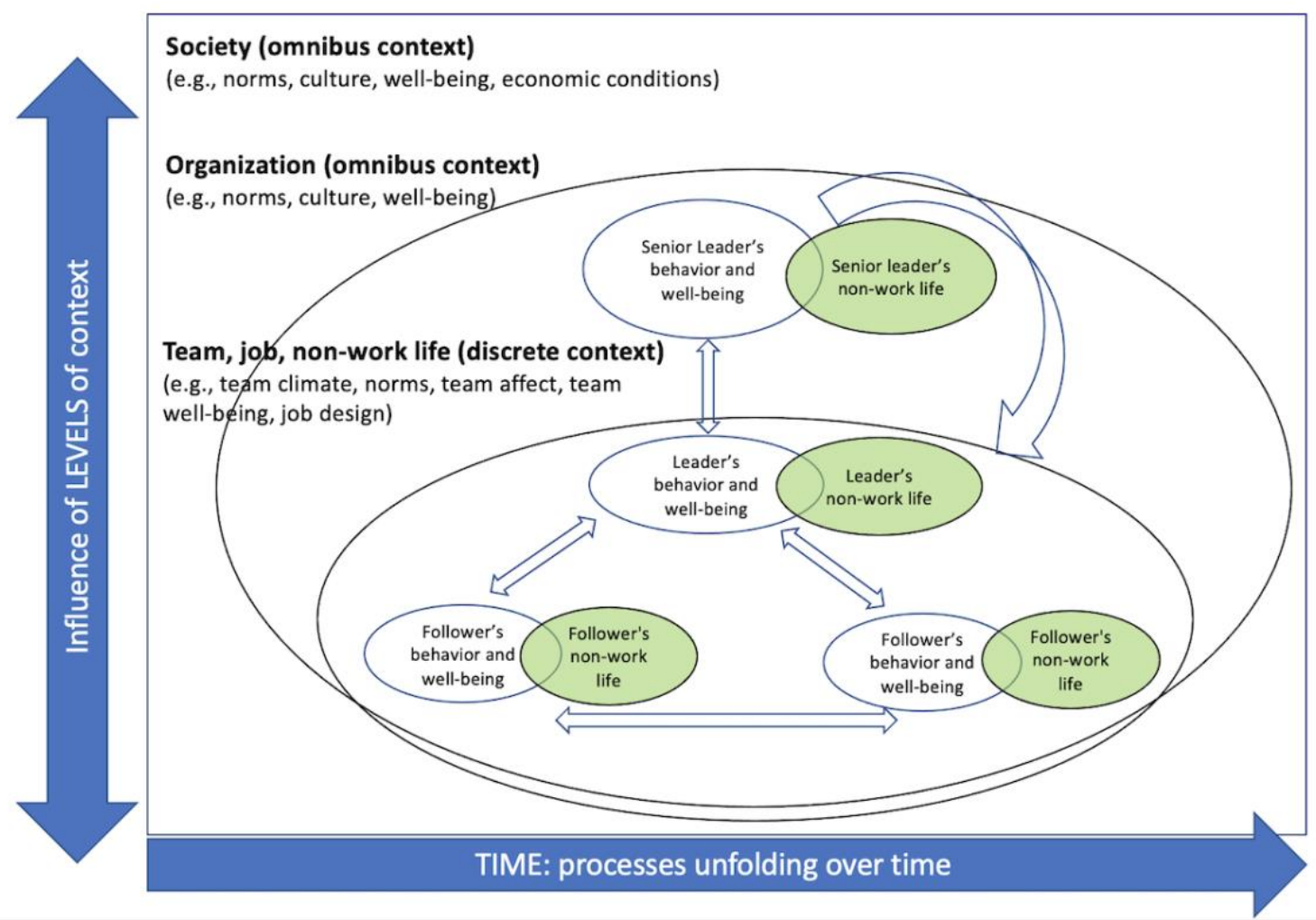

At the heart of Lewin's (1942) force field theory is the proposition that behaviour is a "function of a multitude of co-existing, interacting and interdependent forces within the person and environment (both social and non-social)" (Papanek, 1973, p. 318-19). Lewin (1942) also considered time and the dynamics of these influences, observing "often, the world looks very different before and after an event" (p. 874). In our model we group these forces under the broad umbrella term of context, defined as "stimuli and phenomena that surround and thus exist in the environment external to the individual, most often at a different level of analysis" (Mowday \& Sutton, 1993, p. 198). Johns (2006) proposed that context can be considered at two levels of analysis: omnibus and discrete context. Simply put, the omnibus context encompasses macro level factors, involving "a broad consideration of contextual or environmental influences" (Oc, 
2018, p. 219). John captures these with three questions: "where", "who" and "when". In our model these factors include societal influences (e.g. norms, culture, economic conditions and well-being) and organizational ones (e.g. organizational culture, norms, well-being at organizational level). Embedded within the omnibus context is the discrete context which refers "to the particular contextual variables or levers that shape behavior or attitudes" (Oc, 2018, p. 391) and involves social, task and physical context. In our model the discrete context includes team climate, norms, team affect, team well-being, job design and non work life. Our model illustrates that these omnibus and discrete contextual factors are, in Lewin's terms, forces that influence leadership and well-being directly and via behaviors and attitudes, over time (i.e. processes unfolding within short or long timeframes). Research questions can be examined at different levels and across levels (represented as layers in the model), starting at the very granular level focusing on well-being which we outline next, using a microscopic perspective.

\section{THE MICROSCOPE: LEADER AND FOLLOWER HEALTH/WELL-BEING}

Well-being is a multi-faceted construct, broadly defined in terms of psychological (feeling good), physical (e.g. bodily functioning) and relational well-being (having high quality social relationships) (e.g. Diener \& Seligman, 2004; Grant et al., 2006; Warr, 2013). Well-being has both stable and variable components so that research typically should account for "baseline" levels and change at the same time. For example, psychological well-being in the form of affect

can be measured at stable (i.e. trait) and state levels, within both long and short-time frames (e.g. Warr, 2013).

Putting well-being under the microscope, research can examine leaders' and followers' health and well-being at a granular level. Various aspects of health and well-being have been the 
focus of research in psychology, organisational behaviour and physiology. For example: physical health (e.g. sleep: Litwiller et al., 2017; Hammer et al., this issue), general psychological wellbeing (e.g. General Health Questionnaire: Goldberg \& Hillier, 1979), work-related well-being (e.g. Warr et al. 2014, Cartwright \& Cooper, 1994; Quick, 1988), well-being outside of work (e.g. life satisfaction: Zhang \& Tu, 2018) and genetic factors which have been linked to wellbeing (e.g. Wurtman, 2005). Advances in (interdisciplinary) research and physiological measurement also make it possible to link physical and psychological aspects of well-being (e.g. stress indicators such as heart rate variability: Cropley et al., 2017; Parker et al., 2020; microbiome and mental and physical health: Liu, 2017).

A microscopic within-person perspective on well-being opens up the view on a dynamic mini force field in Lewin's terms and might reveal dynamics and tensions between, for example, psychological and physiological forms of well-being. Research on stress response, interoceptive awareness demonstrates that individuals who experience high levels of stress may be less aware of their own physical needs (e.g. Price \& Hooven, 2018). Senior managers or entrepreneurs who work in high pressure roles, for example, can work to the point of breakdown/burnout without noticing declining levels of well-being (e.g. Williamson et al., 2021). Leader and follower interactions can result in physiological responses that provide additional insights going beyond the leader's and followers' self-perceptions. For example, well-being as reflected in stress responses in the form of cortisol levels and heart rate variability as well as positive reactions through the release of oxytocin, as observed in relationships with positive social bonds (e.g. Algoe et al., 2017). Research in this area and interest in practical applications in organisations is growing and will benefit from interdisciplinary work. For example, the rapid development of physiological measurement of well-being using wearable and mobile technology (e.g. Cropley et 
al., 2017; Ponzo et al., 2020) has opened up possibilities for studying leadership and health/wellbeing at a granular level, going beyond self-report survey measures. With these growing possibilities, future research also needs to consider ethical implications of using technology to assess and support well-being in leadership processes in organisations.

A microscopic between-person perspective of well-being can increase researchers' understanding of how leader and follower well-being might be related, how each might be affected by the others' well-being and how leaders' and followers' baseline levels of well-being might be associated with their behaviors and interactions at future times. Recent work has started to pay attention to the leaders' own health/well-being (e.g. Barling \& Cloutier, 2017; Kaluza et al., 2019). This can affect behaviors in many ways. Leaders with higher levels of well-being are more likely to adopt constructive, rather than destructive forms of leadership (Byrne et al., 2014; Kaluza et al., 2019), they might take their own well-being and that of their team/followers more seriously, and have more personal resource or empathy when it comes to their employees' wellbeing (Byrne et al., 2014; Felfe \& Pundt, 2014). Healthy leaders are also more likely to set positive examples and encourage healthy work behaviors (Felfe \& Pundt, 2014). Koch and Binnewies (2015), for instance, found that followers who set boundaries between work and nonwork, had leaders who enacted/role modelled these behaviors. A leader who feels burned out by contrast, will not be able to put a high level of energy into leading and providing support to their followers and is more likely to show destructive forms of leadership (Byrne et al., 2014; Kaluza et al., 2019). For example, leaders' poor sleep quality has been associated with abusive behaviors towards followers (Barnes et al, 2015).

The health/well-being of the follower is typically measured as an outcome or mediator variable in research on leadership and health/well-being (e.g. employee mental health: Montano 
et al., 2017) with many studies focusing on psychological, hedonic forms of well-being (e.g. Inceoglu et al., 2018). However, alternative relationships and forms of well-being could be considered. The followers' health/well-being may function as a predictor, changing interactions with the leader and evaluations of leadership. For example, followers with mental health issues will need more support from their leaders who might not be equipped to detect this need and/or not be able to provide the required support (Barling \& Cloutier, 2017; Dimoff \& Kelloway, 2019; Dimoff et al., 2016).

Both the leaders' and followers' personality, motivation, values and attitudes towards work and health also matter for their interactions with each other and can impact their wellbeing. For example, leaders with high achievement goals might increase the risk of follower burnout (Sijbom et al., 2018) by raising high expectations, putting high demands on followers and perhaps being less aware of when followers' resources start to deplete. Conversely, Shen et al. (this issue) identify follower poor performance as a source of leader emotional exhaustion. This is because poor performance triggers leaders to engage in more abusive supervision, which in line with Stress-as-an-Offensive to Self theory (Semmer et al., 2019) is particularly detrimental to leader well-being when their abusive supervision is motivated by injury motives.

Research and empirical findings on leadership and well-being of followers and leaders are not always intuitive - pointing in Lewin's terms to different forces that are at play when examining leadership behaviour and employee well-being. For instance, Boekhorst et al. (this issue) studied manager caring behavior. Intuitively, one could assume that managers' caring behavior will improve follower well-being. In contrast to this intuitive idea, Boekhorst et al provide a much more nuanced view suggesting that manager caring behavior can also have negative consequences by making followers feel guilty. 
Another avenue that could be explored in future research focuses on reciprocal relationships between leader and employee well-being (dyads and teams). These relationships are depicted in the Figure as arrows between leaders and followers, as well as arrows between followers. While current work is beginning to explore leader well-being in and of itself as potentially differentiated from employee well-being, theoretical arguments suggest that wellbeing in one might be related to the other and there exists a possibility for either negative or positive spirals (such as those described by COR theory (Hobfoll, 1989; Hobfoll et al., 2018). For example, well-being in the form of emotional exhaustion and engagement can cross over from team members to leaders (Wirtz et al., 2017). A novel approach to study these processes can be drawn from the perspective of climate emergence (Barsade, 2002) viewing the affective climate of a group as a joint product of group interactions (Kozwlowski \& Klein, 2000). Advances in research methodology also allow researchers to specifically examine the contribution of particular types of individuals such as leaders or followers to group climates (Lang, Bliese \& de Voogt, 2018). Investigations into processes from different perspectives, considering reciprocal, vertical and horizontal relationships might also encourage future research on concepts such as shared leadership (Mertens et al., 2020) and social networks of followers and leaders (e.g. Cullen-Lester et al., 2016).

In sum, the microscopic view can help unpack micro processes and micro forces (in Lewin's terms) that influence the leader's and followers' health/well-being and their interactions with each other which in turn also impact their health/well-being. Future research needs to examine these processes by also considering the nestedness of leaders and followers within shared and co-created experiences (e.g. climate emergence). We discuss contextual influences next. 


\section{THE MACROSCOPE: IMPORTANCE OF CONTEXT FOR LEADERSHIP AND WELL-BEING RESEARCH}

Context matters, but is rarely investigated as a moderator or direct influence on leadership and health/well-being. The omnibus and direct context (Johns, 2006) in which leaders and followers operate in and interact with each other, is in Lewin's terms, a forcefield, with a multitude of variables that can influence behavior of the leader and follower and their dyadic (and team) relationship (Oc, 2018) - which are all relevant for well-being. These considerations have been fairly absent in the field.

Past research has tended to focus on direct supervisors' behaviour when assessing leadership styles, without specifying the level of the organization that the leader and employee are located at (omnibus context). This could create ambiguity regarding how/whether hierarchical level has a role to play in these relationships (Hancock et al., in press). For example, an employee without supervisory responsibility reporting to a front-line supervisor might report differing well-being than a VP reporting to a CEO, even if they both report to constructive leaders, but these differences might be a function of work factors other than leadership (e.g., autonomy, supports, pay etc.). And how is well-being impacted if an individual is both a leader (in a supervisory role) and a follower?

Levels of leadership also have implications for the leader's own health/well-being: while higher levels of leadership are typically associated with greater decision making authority and autonomy, they also entail higher levels of demands (Hambrick et al., 2005). Leaders who are both owners and founders of the organizations they manage (i.e., entrepreneurs: Stephan, 2018) face key stressors such as extensive workloads and high uncertainty (Rauch et al., 2018) and, despite the decision latitude that comes with their role, often encounter unrecognized constraints 
on their autonomy (e.g. from stakeholders such as investors, key customers and governance boards: e.g. van Gelderen, 2016).

Some contexts (e.g. industry sector, organizational culture) might restrict variability in leadership behavior which has implications for the leader's own well-being (e.g. lower levels of autonomy) and that of their followers. For example, Hackman (2003) found that cockpit teams are under the strong influence of context variables such as cockpit technology, regulatory procedures and standards, leaving "almost no variation across airlines" (p. 910) to be explained in the design of the flying task and the design of the crew itself" and very little variance in captains' leadership style.

A more comprehensive and multi-layered perspective on context encourages modelling such differences in the variability of the leader's influence, the distance to the leader (e.g. influence of CEOs: Clark et al., 2014) and situational constraints leaders act in. While the leadership literature has started paying attention to levels of leadership (for example, in relation to firm performance: Clark et al., 2014), research on leadership and health/well-being has neglected to account for the extent to which the behavior and well-being of a leader can influence the well-being of the follower by appropriately using multilevel analyses to study, for example, the emergence of climates (discrete context), or more fine-grained dyadic actor-partner models. Such approaches can also help understand, for example, whether and how attitudes of senior leaders shape (via cascading processes) climate and attitudes towards well-being in an organization (e.g. setting positive or negative examples).

Industry sector and organizational culture are examples of omnibus context factors that influence a leader's and their followers' well-being directly and through team climate, job design (both examples of discrete context) and perceptions of leadership (Oc, 2018). For instance, in 
industry sectors that have traditionally been characterized by long working hours and high job demands such as finance and banking, it may not be viewed as "acceptable" to show vulnerability and may be more difficult and risky to discuss mental health issues (as a leader and follower). Boekhorst et al. (this issue) found that in teams with a low caring climate, manager caring behavior can signal role overload to employees - so possibly unintended negative perceptions of difficulties in navigating their own workload.

The generalizability of findings from one industry sector to other contexts is an important question to address that remains underexplored. For instance, the paper by Hammer et al (this issue) examined an intervention in the military, specifically developed for and implemented with leaders and employees operating in this context. Industry sectors also differ in terms of competitiveness, pace of change, and the caring or prosocial motivations of their workforce (e.g., consider working at a multinational technology company focusing on e-commerce, a social media start-up, or government social services or health care).

Across countries levels of well-being (Steel et al., 2018) as well as implicit theories of effective leadership vary (Javidan et al, 2006). For instance, leaders behaving in contradiction with culturally endorsed implicit leadership theories may create uncertainty and stress for their followers, and themselves. Moreover, context can drive self-selection such that different individuals choose to become leaders or entrepreneurs altogether depending on the culturally endorsed leadership prototypes in a country (Stephan \& Pathak, 2016). Such leaders or entrepreneurs might have different baseline levels of well-being because of self-selection processes.

Furthermore, it may be the configuration of different dimensions of omnibus context including formal institutions (such as the existence of a strong rule of law, regulations and 
welfare states) in combination with culture and informal institutions that form supportive or adverse contexts or ecosystems for leadership and well-being/health. An ecosystem encompasses "co-evolution and mutualistic interdependence among a complex nested system of diverse organizations and actors" (Stam \& van de Ven, 2021, p. 811, citing Hawley, 1950). In supportive ecosystems, both leader and follower well-being may thrive, while in adverse ecosystems leaders may play a particularly critical role for follower well-being as 'good leadership' may compensate, for instance, for the inequities and inequalities created by weak formal institutions.

Diversity of leadership is another example of omnibus context that has been neglected in research on leadership and well-being: much of the work looking at how leaders affect employee well-being does not explicitly analyse gender, race, age, or other diversity dimensions (other than perhaps controlling for some of these variables in a minority of published studies: e.g., Hancock et al., in press, regarding gender). Considering diversity of both leaders and followers and the relationship this has on leadership and well-being is an important future direction. Pajic et al. (this issue) offer important insights in terms of follower diversity. Using meta-analysis and a large-scale representative survey, they demonstrate that leadership is more consequential for the wellbeing of followers from low (vs. high) socio-economic status backgrounds (i.e., those with low education working in low status jobs earning low incomes).

Another aspect of (discrete) context involves the interaction between the work and nonwork sphere and circumstances (e.g. Allen et al., 2014) of leaders and followers. As our model depicts, work and non-work are both important spheres that could be considered when parsing out the effects of leadership on the leader's and followers'/team's well-being. Hammer et al (this issue) examine the impact of a health/well-being intervention on leaders and employees by also considering the extent to which leaders show family supportive behaviors. 
Not least, the Covid-19 pandemic had drawn attention to the importance of time and temporal dynamics in leadership and health/well-being. It has highlighted how rapidly context and uncertainty can change, resulting in constantly shifting demands on leaders (Hartlaub et al., in press) at all levels in society and in organizations, as well as well-documented pressures on well-being and health of leaders and employees. However, even in 'normal' times, changes in context can happen but tend to be underestimated. Employees can experience changes in job demands (aspects of discrete context) from one day to the next and the extent to which job demands vary has been shown to amplify the relationship between job demands and well-being (Downes et al. 2021). Yet research that considers temporal dynamics in leadership and health/well-being explicitly (e.g. Breevaart et al., 2014) is still emergent. Several papers in this special issue examine the role of time explicitly or implicitly. Fletcher and French (this issue) examine the impact of transitioning into a first-time leadership role on well-being over a timeframe of 12 years with data collected every one to two years. Results of their study reveal that individuals experience tensions at the time of first moving into a leadership role, but that over time their emotional well-being and self-esteem grow. The intervention studies in this issue by Hammer et al., Stein et al. and Vonderlin et al. incorporate change by design, showing how well-being focused leadership training increases the well-being of followers and/or leaders. Shen et al. (this issue) examine within-person dynamics in the relationship between abusive supervision and leader well-being in a diary study.

In summary, research could be more ambitious, uncovering how leadership as a social process and health/well-being unfold over time, embedded in different layers of contextual influences. 


\section{Working with the microscope and macroscope: Methodological challenges}

Studying leadership and well-being in organizations poses a number of methodological and analytical challenges for researchers. One methodological challenge is to link multiple groups of different people within an organization without facing too many issues around missing data and data validity. The Bernerth et al. paper in this special issue contributes to this challenge by presenting a novel approach for validating data in studies on leadership and avoiding false data because of incorrect identities.

As illustrated in our model, another methodological challenge is that leadership in organizations is a multilevel construct and can be viewed from several different multilevel perspectives (Bliese et al., 2002; Bliese et al., 2018; Haslam et al., 2019; Yammarino \& Dansereau, 2008). First, leadership can be defined as an individual perception of a dyadic relationship (follower-leader). Second, leadership can be seen as the unique individual perception of a dyadic relationship relative to the perception of other group members. Third, leadership can be viewed as a shared perception of the follower-leader relationships or the leader's interaction with the group by the group members. Fourth, leadership can be described as a leader's self-perception of his/her interaction with the group. Finally and fifth, leadership can also be operationalized as a simple nesting variable whereby the presence of a leader affects unit or individual outcomes (Lang et al., 2018). A similar level of complexity exists for well-being where the individual level perception of well-being, the individual perception relative to the group mean, and also the shared perception of well-being/stress are all possible operationalizations of well-being in organizations within multilevel theorizing. From a theoretical point of view, a particularly interesting question is whether well-being can be 
conceptualized as a shared phenomenon, similar to group affective tone (Barsade, 2002; George, 1990; Lang et al., 2018; Loh et al., this issue). Several papers in the special issue contribute to this debate. Vonderlin et al., Stein et al., and Hammer et al. conducted intervention studies showing that interventions targeting supervisors also affected the well-being of the supervisors' employees. Loh et al. studied antecedents of the emergence of unit-level psychosocial safety climate and showed that leadership affects the PSC level and consensus emergence.

A second fundamental challenge for studying leadership and well-being in organizations is the fact that it is not always clear that leader behavior is necessarily distinct from follower behavior. Most leadership research uses measures for leadership that are distinct from the measures used to assess the behavior/perceptions of followers. However, a critical question discussed in a small number of papers in the leadership literature is whether formal leaders are really so distinct from followers (e.g., Collinson et al., 2018). Would the same results emerge when individuals completed the leadership measure for a randomly selected follower instead of the leader? From the perspective of well-being research, it is also possible that the well-being leader of a group and the task/formalized leader of the group are not identical. One approach for addressing these challenges and research questions is to study leaders and followers using the same measures and to then statistically establish that leaders differ from followers (Lang et al., 2018) or that leader perceptions/behavior explains outcomes beyond the followers' own behavior (Sijboom et al., 2019). Another approach is to manipulate leader behavior through interventions like the three intervention studies in the special issue did. These studies contribute to his discussion by showing that intervening at the level of formal supervisors actually has effects on follower well-being. 
A third methodological challenge for studying leadership and well-being in organizations pertains to phenomena unfolding over time. More theory guided research is needed to choose the appropriate timeframes and predict change/variability in leadership and well-being constructs. For example, while individual perceptions of leadership behaviour and well-being can potentially change quickly, shared perceptions and climates are likely to develop through repeated interactions of leaders and followers over longer periods of time. Studying the emergence of the constructs of interest over time will help gain a deeper understanding of shared perceptions of leadership and well-being. Especially studies that can provide insights into how well-being can "spillover" or "spread" in organizations over time are of interest for the field in better understanding to what degree well-being is a collective phenomenon.

A final and fourth methodological challenge for understanding and studying leadership and well-being in organizations, centers around causality and the potential to actually improve either well-being relevant leadership or well-being in leaders and followers themselves. One approach for studying this question are experimental field studies, for example in the form of intervention studies which we discuss below. From a multilevel perspective, one basic question is which organizational level and collective or individual constructs should be targeted by interventions and to what degree the climate of the environment facilitates or hampers change. A question for future research is whether these types of interventions are more likely to produce change in well-being than those focused solely on either leaders or followers without including the other. Future research would benefit from combining randomised controlled field experiments with approaches using machine learning to determine causal relationships (Lee et al., 2020). 


\section{FROM THE MICROSCOPE AND MACROSCOPE INTO THE REAL WORLD: INTERVENTION STUDIES ON HEALTH/WELL-BEING}

Intervention studies to increase health/well-being in an organizational context are rare in comparison to alternative research methods (Roodbari et al., 2021) as they are often difficult to conduct (e.g., Beehr, 2019). This is an unfortunate state of affairs as intervention studies are a gateway towards practical impact (e.g. improving health: Steffens et al., 2017). Akin to the biomedical profession, the "medicine" that flows out of our theoretical insights are the things that influence practice. Especially when it comes to enhancing employee well-being, there are a plethora of interventions or apps offered by consultants, often involving significant cost, with little evidence that they actually work (e.g., Lau et al., 2020). We have a responsibility as academics to inform the public with good research about what does/doesn't work.

Our special issue includes several intervention studies that provide evidence-based interventions that promote leader or employee well-being (Hammer et al.; Stein et al.; Vonderlin et al, all this issue). The evidence is clear but also nuanced - there is no magic bullet out there and different interventions should be weighed for their practical relevance in particular constellations. There is a greater need for intervention studies to consider what works under which preconditions or circumstances. This requires a greater consideration of dynamic contexts in the design of a study and also greater consideration of how the effects may or may not translate into different contexts.

The intervention studies in this special issue demonstrate important practical value. While conducting this type of study, it can sometimes be a challenge to highlight theoretical focus. This highlights an interesting opportunity for future intervention studies (which are sorely needed) to design their studies to not only prove that the intervention works, but to also consider why and 
how exactly the intervention works. Hammer et al. examine processes accounting for change in employee well-being related to the Total Worker Health intervention assessed. Results of their cluster randomized controlled trial show an improvement in several aspects of well-being (e.g. reduced stress before bedtime), and begin to unpack the reasons for those changes. Vonderlin's intervention study targets the leader's self-care and staff care, resulting in increased well-being for leaders. Stein et al.'s study (this issue) investigated the effectiveness of supportive leader behaviour training and demonstrates that not all employees might equally benefit from the leaders' (changed) supportive approach: well-being increased more for employees with higher workloads.

Examining why interventions work is an important question to be considered for future research, and strong theory could be quite practical here (Van de Ven, 1989). Intervention studies can have great potential to highlight theoretical applications. Or as Kurt Lewin stated: "If you really want to understand something, try to change it."

\section{The Contribution of this Special Issue}

In this editorial, we presented a micromacrosope as a conceptual framework to think about leadership and health/well-being. This framework illustrates how in Lewin terms "forces" operate and interact at different levels and can be thought of from an ecosystems perspective. Important implications for theory and practice arise when we start thinking beyond isolated relationships in the system. The papers in the special issue contribute to key elements in the framework - the microscope, the macroscope and relationships within each across time and context levels - in several ways. Table 1 highlights these contributions for each of the papers. It is noteworthy that several papers consider changes over time (ranging from daily fluctuations to changes across more than a decade) in leadership processes and relationships with leader and/or 
employee health/well-being. Nonetheless, the framework also shows several important areas where future research is still needed. For example, most of the studies in this special issue presented in Table 1 target a specific aspect within the framework, focusing on microscopic perspectives. Future research could develop more comprehensive research designs that integrate microscopic and macroscopic perspectives. For instance, by combining intervention studies with multi-level approaches to understand how within-unit, between-unit relationships are affected by interventions. These papers all make important advances to the literature on leadership and health/well-being, and we hope they stimulate future research that addresses the complexity reflected in this area.

Table 1: Overview of papers in this special issue

\begin{tabular}{|c|c|c|c|c|}
\hline Authors & Microscope & Macroscope & Methodological & Intervention \\
\hline Bernerth et al. & & & $\begin{array}{l}\text { Validating } \\
\text { identities in } \\
\text { leadership studies } \\
\text { to ensure that } \\
\text { researchers are } \\
\text { actually studying } \\
\text { the organizational } \\
\text { structures the } \\
\text { believe they study }\end{array}$ & \\
\hline Boekhorst et al. & $\begin{array}{l}\text { A nuanced } \\
\text { perspective on } \\
\text { positive and } \\
\text { negative effects of } \\
\text { manager caring } \\
\text { behavior for } \\
\text { employees }\end{array}$ & $\begin{array}{l}\text { Moderating role } \\
\text { of team caring } \\
\text { climate }\end{array}$ & $\begin{array}{l}\text { Development of a } \\
\text { scale measuring } \\
\text { manager caring } \\
\text { behavior. Multi- } \\
\text { level model taking } \\
\text { into account that } \\
\text { employees are } \\
\text { nested within } \\
\text { teams }\end{array}$ & \\
\hline
\end{tabular}




\begin{tabular}{|c|c|c|c|c|}
\hline $\begin{array}{l}\text { Fletcher \& } \\
\text { French }\end{array}$ & $\begin{array}{l}\text { Tensions } \\
\text { experienced when } \\
\text { moving into the } \\
\text { first leadership } \\
\text { role and well- } \\
\text { being in the } \\
\text { longer term }\end{array}$ & $\begin{array}{l}\text { Transition and } \\
\text { time: } \\
\text { longitudinal over } \\
12 \text { years }\end{array}$ & & \\
\hline Hammer et al. & $\begin{array}{l}\text { Examines why } \\
\text { Total Worker } \\
\text { Health } \AA \\
\text { intervention } \\
\text { (supervisor } \\
\text { training related to } \\
\text { support for sleep } \\
\text { health and family } \\
\text { supportive } \\
\text { behaviours; health } \\
\text { promotion } \\
\text { training related to } \\
\text { sleep for } \\
\text { employees) is } \\
\text { effective; focus on } \\
\text { multiple well- } \\
\text { being outcomes }\end{array}$ & $\begin{array}{l}\text { Change over } \\
\text { time }\end{array}$ & & $\begin{array}{l}\text { Cluster } \\
\text { randomised } \\
\text { controlled trial }\end{array}$ \\
\hline Loh et al. & $\begin{array}{l}\text { Leadership styles } \\
\text { affect emergence } \\
\text { of collective } \\
\text { follower } \\
\text { interactions }\end{array}$ & $\begin{array}{l}\text { Change over } \\
\text { time }\end{array}$ & $\begin{array}{l}\text { Use of extended } \\
\text { multilevel } \\
\text { approach across } \\
\text { time }\end{array}$ & \\
\hline Pajic et al. & $\begin{array}{l}\text { Link between } \\
\text { constructive and } \\
\text { destructive forms } \\
\text { of leadership, } \\
\text { employee } \\
\text { resources and } \\
\text { well-being }\end{array}$ & $\begin{array}{l}\text { Follower } \\
\text { socioeconomic } \\
\text { status (SES) } \\
\text { moderates the } \\
\text { relationship } \\
\text { between } \\
\text { leadership and } \\
\text { follower } \\
\text { wellbeing }\end{array}$ & $\begin{array}{l}\text { Meta-analysis of } \\
241 \text { independent } \\
\text { samples and large- } \\
\text { scale } \\
\text { representative } \\
\text { study }(\mathrm{N}=62,602)\end{array}$ & \\
\hline $\begin{array}{l}\text { Shen, Liang, } \\
\text { Brown, Ni \& }\end{array}$ & $\begin{array}{l}\text { Dyadic processes. } \\
\text { Follower poor }\end{array}$ & $\begin{array}{l}\text { Change over } \\
\text { time }\end{array}$ & $\begin{array}{l}\text { Study 1: Multi- } \\
\text { wave multi-source }\end{array}$ & \\
\hline
\end{tabular}




\begin{tabular}{|c|c|c|c|c|}
\hline Zheng & $\begin{array}{l}\text { performance } \\
\text { reduces leader } \\
\text { wellbeing through } \\
\text { enhancing leader } \\
\text { abusive } \\
\text { supervision, and } \\
\text { contingent on } \\
\text { leader motives for } \\
\text { abuse }\end{array}$ & & $\begin{array}{l}\text { field study of } \\
\text { leader dyads, } \\
\text { Study 2: Two- } \\
\text { week daily diary } \\
\text { study, as well as } \\
\text { Pilot study: Multi- } \\
\text { wave field study }\end{array}$ & \\
\hline Stein et al. & $\begin{array}{l}\text { Supportive } \\
\text { leadership training } \\
\text { increased } \\
\text { employee well- } \\
\text { being; employees } \\
\text { with higher } \\
\text { workloads } \\
\text { benefitted more }\end{array}$ & $\begin{array}{l}\text { Change over } \\
\text { time }\end{array}$ & & $\begin{array}{l}\text { Randomised } \\
\text { controlled trial }\end{array}$ \\
\hline Vonderlin et al & $\begin{array}{l}\text { Leadership } \\
\text { training increased } \\
\text { leaders' self and } \\
\text { staff care and } \\
\text { leaders' well- } \\
\text { being }\end{array}$ & $\begin{array}{l}\text { Change over } \\
\text { time }\end{array}$ & & $\begin{array}{l}\text { Quasi- } \\
\text { experimental } \\
\text { field study }\end{array}$ \\
\hline
\end{tabular}




\section{REFERENCES}

Algoe, S. B., Kurtz, L. E., \& Grewen, K. (2017). Oxytocin and social bonds: The role of oxytocin in perceptions of romantic partners' bonding behavior. Psychological Science, 28(12), $1763-1772$.

Allen, T. D., Cho, E., \& Meier, L. L. (2014). Work-family boundary dynamics. Annual Review of Organizational Psychology and Organizational Behavior, 1(1), 99-121.

Arnold, K. A. (2017). Transformational leadership and employee psychological wellbeing: A review and directions for future research. Journal of Occupational Health Psychology, $22(3), 381-393$.

Bamberger, P. (2008). From the Editors Beyond Contextualization : Using Context Theories To Narrow the Micro-Macro Gap in. Academy of Management Journal, 51(5), 839846.

Barling, J., \& Cloutier, A. (2017). Leaders' mental health at work: Empirical, methodological, and policy directions. Journal of Occupational Health Psychology, 22(3), 394.

Beehr, T. A. (2019). Interventions in occupational health psychology. Journal of Occupational Health Psychology, 24(1), 1-3.

Bliese, P. D., \& Jex, S. M. (2002). Incorporating a mulitilevel perspective into occupational stress research: Theoretical, methodological, and practical implications. Journal of Occupational Health Psychology, 7(3), 265-276.

Bliese, P. D., Maltarich, M. A., \& Hendricks, J. L. (2018). Back to basics with mixedeffects models: Nine take-away points. Journal of Business and Psychology, 33(1), 1-23 
Barnes, C. M., Lucianetti, L., Bhave, D. P., \& Christian, M. S. (2015). "You wouldn’t like me when I'm sleepy": Leaders' sleep, daily abusive supervision, and work unit engagement. Academy of Management Journal, 58(5), 1419-1437.

Barsade, S. G. (2002). The ripple effect: Emotional contagion and its influence on group behavior. Administrative Science Quarterly, 47(4), 644-675.

Byrne, A., Dionisi, A., Barling, J., Akers, A., Roberston, J., Lys, R., Wylie, J., \& Dupre, K. (2013). The depleted leader: The influence of leaders' diminished psychological resources on leadership behaviors. The Leadership Quarterly, 25(2), 344-357.

Collinson, D., Jones, O. S., \& Grint, K. (2018). 'No more heroes': Critical perspectives on leadership romanticism. Organization Studies, 39(11), 1625-1647.

Clark, J. R., Murphy, C., \& Singer, S. J. (2014). When do leaders matter? Ownership, governance and the influence of CEOs on firm performance. Leadership Quarterly, 25(2), 358372.

Cooper, C. L., \& Cartwright, S. (1994). Healthy mind; healthy organization-A proactive approach to occupational stress. Human Relations, 47(4), 455-471.

Cropley, M., Plans, D., Morelli, D., Sütterlin, S., Inceoglu, I., Thomas, G., \& Chu, C. (2017). The association between work-related rumination and heart rate variability: a field study. Frontiers in Human Neuroscience, 11, 27.

Diener, E., \& Seligman, M. E. P. (2004). Beyond money. Psychological Science in the Public Interest, 5(1), 1-31.

Dimoff, J. K., \& Kelloway, E. K. (2019). With a little help from my boss: The impact of workplace mental health training on leader behaviors and employee resource utilization. Journal of Occupational Health Psychology, 24(1), 4. 
Dimoff, J. K., Kelloway, E. K., \& Burnstein, M. D. (2016). Mental health awareness training (MHAT): The development and evaluation of an intervention for workplace leaders. International Journal of Stress Management, 23(2), 167-189. https://doi.org/10.1037/a0039479

Downes, P. E., Reeves, C. J., McCormick, B. W., Boswell, W. R., \& Butts, M. M. (2021). Incorporating job demand variability into job demands theory: A meta-analysis. Journal of Management, 47(6), 1630-1656.

Felfe, F.F. \& Pundt, J. A. (2014) The impact of health-oriented leadership on follower health: development and test of a new instrument measuring health-promoting leadership. German Journal of Human Resource Management, 28(1-2),139-161.

George, J. M. (1990). Personality, affect, and behavior in groups. Journal of Applied Psychology, 75(2), 107.

Gelderen, M. V. (2016). Entrepreneurial autonomy and its dynamics. Applied Psychology, 65(3), 541-567.

Goldberg, D. P., \& Hillier, V. F. (1979). A scaled version of the General Health Questionnaire. Psychological Medicine, 9, 139-145.

Hackman, J. R. (2003). Learning more by crossing levels: evidence from airplanes, hospitals, and orchestras. Journal of Organizational Behavior, 24(8), 905-922.

Hambrick, D. C., Finkelstein, S., \& Mooney, A. C. (2005). Executive job demands: New insights for explaining strategic decisions and leader behaviors. Academy of Management Review, 30(3), 472-491.

Harms, P.D, Credé, M., Tynan, M., Leon, M. \& Jeung, W. (2017). Leadership and stress: A meta-analytic review. The Leadership Quarterly, 28(1), 178-194. 
Hartlaub, D., Inceoglu, I., Hernandez Bark, A., \& Kark, R. (in press). Is it stressful at the top? The stress of leadership in times of stability and crisis. In Laurent M. Lapierre and Cary Cooper (Eds). Cambridge Companion to Organisational Stress and Well-being. Cambridge, UK: Cambridge University Press.

Haslam, S. A., Steffens, .N. K., \& Peters, K. (2019).The importance of creating and harnessing a sense of 'us': social identity as the missing link between leadership and health. Social scaffolding: applying the lessons of contemporary social science to health and healthcare. (pp. 302-311) edited by Richard Williams, Verity Kemp, S. Alexander Haslam, Catherine Haslam, Kamaldeep S. Bhui and Sue Bailey. Cambridge, United Kingdom: Cambridge University Press. doi: 10.1017/9781911623069.029

Hawley, A. (1950). Human ecology: A theory of community structure. New York: Ronald Press.

Hancock, A.J., Daher Moreno, E.N., \& Arnold, K.A. (in press). The role of line managers in promoting and protecting employee well-being. Cooper, C. \& Lapierre, L. (Eds.). In Organisational Stress and Well-being. Companions to Management Series: Cambridge University Press.

Hobfoll, S.E. 1989. Conservation of resources. A new attempt at conceptualizing stress. The American Psychologist, 44(3), 513-524.

Hobfoll, S.E., Halbesleben, J., Neveu, J.P., \& Westman, M. 2018. Conservation of Resources in the Organizational Context: The Reality of Resources and Their Consequences. Annual Review of Organizational Psychology and Organizational Behavior, 5, 103-28. 
Inceoglu, I., Thomas, G., Chu, C., Plans, D., \& Gerbasi, A. (2017). Leadership behavior and employee well-being: An integrated review and a future research agenda. The Leadership Quarterly, 29(1), 179-202.

Javidan, M., Dorfman, P. W., De Luque, M. S., \& House, R. J. (2006). In the eye of the beholder: Cross cultural lessons in leadership from project GLOBE. Academy of Management Perspectives, 20(1), 67-90.

Johns, G. (2006). The essential impact of context on organizational behavior. Academy of Management Review, 31(2), 386-408.

Lang, J. W. B., Bliese, P. D., \& de Voogt, A. (2018). Modeling consensus emergence using longitudinal multilevel models. Personnel Psychology, 71(2), 255-281.

Lee, A., Inceoglu, I., Hauser, O., \& Greene, M. (2020). Determining causal relationships in leadership research using Machine Learning: The powerful synergy of experiments and data science. The Leadership Quarterly (online pre-print version).

Koch, A. R., \& Binnewies, C. (2015). Setting a good example: supervisors as work-lifefriendly role models within the context of boundary management. Journal of Occupational Health Psychology, 20(1), 82-92.

Lewin, K. (1939). Field theory and experiment in social psychology: Concepts and methods. American Journal of Sociology, 44(6), 868-896.

Lewin, K. (1943). Defining the field at a given time. Psychological Review, 50(3), 292310.

Litwiller, B., Snyder, L. A., Taylor, W. D., \& Steele, L. M. (2017). The relationship between sleep and work: A meta-analysis. Journal of Applied Psychology, 102(4), 682-699 
Liu, R. T. (2017). The microbiome as a novel paradigm in studying stress and mental health. American Psychologist, 72(7), 655-667.

Montano, D., Reeske, A., Franke, F., Huffmeir, J. (2017). Leadership, followers' mental health and job performance in organizations: A comprehensive meta-analysis from an occupational health perspective. Journal of Organizational Behavior, 38(3), 327-350.

Mowday, R. T., \& Sutton, R. I. (1993). Organizational behavior: Linking individuals and groups to organizational contexts. Annual Review of Psychology, 44, 195-229.

Quick, J. C. (1998). Introduction to the measurement of stress at work. Journal of Occupational Health Psychology, 3(4), 291-293.

Oc, B. (2018). Contextual leadership: A systematic review of how contextual factors shape leadership and its outcomes. Leadership Quarterly, 29(1), 218-235. https://doi.org/10.1016/j.leaqua.2017.12.004

Papanek, M. L. (1973). Kurt Lewin and his contributions to modern management theory. In Academy of Management Proceedings, 1, 317-322.

Parker, S. L., Sonnentag, S., Jimmieson, N. L., \& Newton, C. J. (2020). Relaxation during the evening and next-morning energy: The role of hassles, uplifts, and heart rate variability during work. Journal of Occupational Health Psychology, 25(2), 83-98.

Ponzo, S., Morelli, D., Kawadler, J. M., Hemmings, N. R., Bird, G., \& Plans, D. (2020). Efficacy of the digital therapeutic mobile app biobase to reduce stress and improve mental wellbeing among university students: randomized controlled trial. JMIR mHealth and uHealth, 8(4), e17767.

Rauch, A., Fink, M., \& Hatak, I. (2018). Stress processes: An essential ingredient in the entrepreneurial process. Academy of Management Perspectives, 32(3), 340-357. 
Roodbari, H., Axtell, C., Nielsen, K., \& Sorensen, G. (2021). Organisational Interventions to Improve Employees’ Health and Wellbeing: A Realist Synthesis. Applied Psychology (online version first published September).

Semmer, N. K., Tschan, F., Jacobshagen, N., Beehr, T. A., Elfering, A., Kälin, W., \& Meier, L. L. (2019). Stress as offense to self: A promising approach comes of age. Occupational Health Science, 3(3), 205-238.

Sijbom, R. B., Lang, J. W., \& Anseel, F. (2019). Leaders' achievement goals predict employee burnout above and beyond employees' own achievement goals. Journal of Personality, 87(3), 702-714.

Sonnentag, S. (2015). Dynamics of Well-Being. Annual Review of Organizational Psychology and Organizational Behavior, 2(1), 261-293. https://doi.org/10.1146/annurevorgpsych-032414-111347

Skakon, J., Nielsen, K., Borg, V. and Guzman, J., 2010. Are leaders' well-being, behaviours and style associated with the affective well-being of their employees? A systematic review of three decades of research. Work \& Stress, 24(2), 107-139.

Stam, E., \& Van de Ven, A. (2021). Entrepreneurial ecosystem elements. Small Business Economics, 56(2), 809-832.

Steel, P., Taras, V., Uggerslev, K., \& Bosco, F. (2018). The Happy Culture: A Theoretical, Meta-Analytic, and Empirical Review of the Relationship Between Culture and Wealth and Subjective Well-Being. Personality and Social Psychology Review, 22(2), 128-169. https://doi.org/10.1177/1088868317721372

Steffens, Niklas K., La Rue, Crystal J., Haslam, Catherine, Walter, Zoe C., Cruwys, Tegan, Munt, Katie A., Alexander Haslam, S., Jetten, Jolanda and Tarrant, Mark (2019). Social 
identification-building interventions to improve health: a systematic review and meta-analysis. Health Psychology Review, 15 (1), 1-28

Stephan, U. (2018). Entrepreneurs' mental health and well-being: A review and research agenda. Academy of Management Perspectives, 32(3), 290-322.

Stephan, U., \& Pathak, S. (2016). Beyond cultural values? Cultural leadership ideals and entrepreneurship. Journal of Business Venturing, 31(5), 505-523.

Williamson, A. J., Gish, J. J., \& Stephan, U. (2021). Let's Focus on Solutions to Entrepreneurial Ill-Being! Recovery Interventions to Enhance Entrepreneurial Well-Being. Entrepreneurship Theory and Practice.

Wirtz, N., Rigotti, T., Otto, K., \& Loeb, C. (2017). What about the leader? Crossover of emotional exhaustion and work engagement from followers to leaders. Journal of Occupational Health Psychology, 22(1), 86-97.

Wurtman, R. J. (2005). Genes, stress, and depression. Metabolism, 54(5), 16-19.

Yammarino, F. J., \& Dansereau, F. (2008). Multi-level nature of and multi-level approaches to leadership. The Leadership Quarterly, 19(2), 135-141.

Zhang, S. \& Tu, Y. (2018). Cross-domain effects of ethical leadership on employee family and life satisfaction: the moderating role of family-supportive supervisor behaviors. Journal of Business Ethics, 152(4), 1085-1097. 